\title{
OPTIMALISASI PENGGUNAAN LAHAN UNTUK TANAMAN JERUK BESAR (Citrus maxima Merr.) BERBASIS EVALUASI LAHAN DAN KELAYAKAN EKONOMI DI KECAMATAN LABAKKANG KABUPATEN PANGKEP
}

\author{
(Optimization of Use of Land forBig Orange Plants (Citrus maxima Merr.) \\ Based on Land Evaluation and Economic Feasibility in Labakkang District, \\ Pangkep District) \\ Karmiati $^{1)}$, Amir Tjoneng ${ }^{2)}$, Edy $^{2)}$ \\ ${ }^{1)}$ Program Studi Magister Agroteknologi, Program Pascasarjana Universitas Muslim Indonesia \\ Email : mhyakarmhyati@gmail.com \\ ${ }^{2)}$ Jurusan Agroteknologi Fakultas Pertanian Universitas Muslim Indonesia
}

\begin{abstract}
The purpose of this study were: 1) determine the suitability of land for large citrus plants in Labakkang District, Pangkep Regency, 2) determine the limiting factors of large citrus plants, 3) analyze the improvement of land for large citrus plants, 4) analyze the economic feasibility of citrus farming big, 5) determine the optimization of the use of large citrus farming land in Labakkang sub-district, Pangkep district. This research was carried out in Labakkang District, Pangkep Regency. Analysis of soil samples was carried out at the Laboratory of Chemistry and Soil Fertility at the Department of Soil Science, Faculty of Agriculture, Hasanuddin University. Land suitability analysis and land suitability criteria based on FAO (1976). The research phase includes the preparation stage, map making, soil sampling and interviews, analysis of soil samples in the laboratory, land suitability analysis and farming analysis. The results showed that the actual land suitability class in the study area was class N2 found in land unit 1, class $S 2$ was on land unit 2,3,4,5,6,7. The dominant limiting factors are water availability, rooting media, available nutrients and erosion hazard level. Grapefruit has an opportunity to be cultivated as indicated by the $R / C$ ratio of 1.72 which means it is beneficial for farmers. Land use obtained from the highest land evaluation with the level of economic income was obtained in the village of Kassilowe with the highest income of a farmer of Rp. 13,000,000 and found in the suitability of potential land for $S 2 r$.
\end{abstract}

Keywords: Land Evaluation, Economic Feasibility

\section{PENDAHULUAN}

Lahan merupakan suatu daerah dipermukaan bumi dengan sifat-sifat tertentu yang meliputi biosfer, atmosfer, tanah, lapisan geologi, hidrologi, populasi tanaman dan hewan serta hasil kegiatan manusia masa lalu dan sekarang, sampai pada tingkat tertentu dengan sifat-sifat tersebut mempunyai pengaruh yang berarti terhadap fungsi lahan oleh manusia pada masa sekarang dan masa yang akan datang. (FAO dalam Sitorus, 2004)

Kebutuhan lahan yang semakin meningkat mengakibatkan berkurangnya lahan pertanian yang unggul sehingga memerlukan optimalisasi penggunaan sumber daya lahan yang memungkinkan tetap tersedianya lahan untuk pertanian secara berkelanjutan. Dengan demikian agar diperoleh hasil yang maksimal dalam penilaian kesesuaian lahan untuk 
Karmiati : Optimalisasi Penggunaan Lahan untuk Tanaman Jeruk Besar (Citrus maxima Merr.) berbasis Evaluasi Lahan dan Kelayakan Ekonomi di Kecamatan Labakkang Kabupaten Pangkep

mendapatkan cara yang tepat yaitu tanaman hortikultura pada dasarnya disesuaikan dengan kegunaannya.

Pemanfaatan lahan yang tidak sesuai dengan kelas kesesuaiannya akan memberikan dampak buruk, baik secara fisik maupun secara ekonomi. Secara fisik, pemanfaatan lahan yang tidak sesuai dengan daya dukung lahan dapat menimbulkan kerusakan lahan (Mather, 1986 dalam Ishak, 2008) dan sebaliknya, penggunaan lahan yang tepat adalah langkah pertama untuk menunjang program konservasi lahan (Sinukaban, 1986 dalam Ishak, 2008). Adapun secara ekonomi, ketidak sesuaian lahan akan berdampak pada produktivitas lahan. Produktivitas komoditas pertanian akan rendah apabila komoditas tersebut ditanam pada lahan dengan kondisi biofisik yang tidak sesuai dengan syarat tumbuh tanaman (Adiwilaga, 1992 dalam Ishak 2008).

Kesesuaian lahan perlu diperhatikan untuk tanaman budidaya untuk mendapatkan pertumbuhan yang optimal, walau tanaman kelihatan dapat tumbuh bersama disuatu wilayah, akan tetapi setiap jenis tanaman mempunyai karakter yang membutuhkan persyaratan yang merupakan bagian integral dan tidak dapat terpisahkan dari pembangunan pertanian dalam upaya mewujudkan program pembangunan nasional. Hortikultura merupakan bidang pertanian yang cukup luas yang mencakup buah-buahan, sayursayuran dan bunga yang secara keseluruhan dapat ditemukan pada ketinggian 0-1000 $\mathrm{m}$ di atas permukaan air laut, maka dari itu areal yang ada di Indonesia hampir seluruhnya dapat digunakan dalam pengusahaan tanaman hortikultura (Rahardi et al, 2003).

Menurut Dinas Pertanian Kabupaten Pangkep, pada tahun 2015 tercatat seluas 1.1614 ha dengan produktifitas 15,441 ton/ha, tapi 2 tahun terakhir sampai 2017 terus mengalami penurunan dengan tingkat produktifitas berkisar 14 ton/ha. Di Kecamatan Ma'rang pada tahun 2016 produksi tanaman jeruk 31.036 ton, pada tahun 201730.861 ton dan Kecamatan Labakkang pada 2016 produkasi tanaman jeruk 6.331 ton dan 2017 sebanyak 3.900 ton. Salah satu penyebab rendahnya produksi dan mutu buah jeruk dapat dilihat dari kesesuaian lahan yang belum begitu cocok dengan tanaman jeruk besar. berbeda-beda. Pembangunan sub sektor 


\section{METODE PENELITIAN}

Teknik pengumpulan data penelitian ini menggunakan pendekatan Survei Sistem Lahan (Intergrated Survey). Tahapan survei lahan meliputi persiapan penelitian yang terdiri atas pengumpulan data sekunder. Penelitian lapang, meliputi survey tanah atau survei sistem lahan, pengumpulan data ekonomi, pengumpulan data produksi. Data ekonomi yang diperoleh selanjutnya dianalisis untuk mengetahui keuntungan atau kerugian petani dari usaha tani jeruk besar, dengan menggunakan rumus $\mathrm{R} / \mathrm{C}$ rasio.

\section{a. Survei Lahan}

Langkah awal dari penelitian ini adalah pembuatan satuan lahan sementara. Satuan lahan merupakan satuan pemetaan yang digunakan pada penelitian ini. Satuan lahan dibuat bedasarkan penentu unsur-unsur unit lahan yang meliputi penggunaan lahan, bentuk wilayah, ladform/litologi dan jenis lahan (Landon, 1984). Pengamatan profil tanah dilakukan berdasarkan Pusat Penelitian Tanah dan Agroklimat (1993).

Tahapan analisis evaluasi lahan dilakukan dengan cara yaitu:

i. Masing-masing komponen karakteristik lahan (fisik) dipetakan sehingga diperoleh peta tematik untuk masingmasing karakteristik lahan, yaitu peta lereng, peta jenis tanah, dan curah hujan.

ii. Peta tematik yang diperoleh, yaitu jenis tanah, topografi, dan curah hujan ditumpang tindih (superimpoded) untuk mendapatkan peta satuan lahan atau satuan peta lahan (SPT), pengambilan sampel tanah diperoleh dari satuan peta tanah dan sampel yang telah diperoleh kemudian dianalisi dilaboratorium.

Data-data yang dibutuhkan untuk analisis tingkat kesesuaian lahan terdiri atas 15 variabel karakteristik lahan yang dikelompokkan kedalam 7 parameter kualitas lahan, seperti pada Tabel 1. 
Karmiati : Optimalisasi Penggunaan Lahan untuk Tanaman Jeruk Besar (Citrus maxima Merr.) berbasis Evaluasi Lahan dan Kelayakan Ekonomi di Kecamatan Labakkang Kabupaten Pangkep

Tabel 1. Parameter Pengukuran Tingkat Kesesuaian Lahan

\begin{tabular}{|c|c|c|}
\hline Simbol & Kualitas Lahan & Karakteristik Lahan \\
\hline $\mathrm{T}$ & Temperatur & - $\quad$ Temperatur tahunan rata-rata \\
\hline $\mathrm{W}$ & Ketersediaan air & $\begin{array}{ll}- & \text { Jumlah bulan kering }(<75 \mathrm{~mm}) \\
- & \text { Curah hujan tahunan rata-rata }(\mathrm{mm}) \\
\end{array}$ \\
\hline $\mathrm{R}$ & Kondisi perakaran & $\begin{array}{ll}- & \text { Kelas drainase } \\
- & \text { Tekstur tanah (permukaan) } \\
- & \text { Kedalaman tanah }(\mathrm{cm}) \\
\end{array}$ \\
\hline $\mathrm{F}$ & Penyerapan hara & $\begin{array}{ll} & \text { KTK (me/100 g) } \\
- & \text { pH (permukaan) } \\
\end{array}$ \\
\hline $\mathrm{N}$ & Ketersediaan hara & $\begin{array}{ll}- & \text { Jumlah N-total }(\%) \\
- & \text { Ketersediaan P2O5 (ppm) } \\
- & \text { Ketersediaan K2O (cmol(+) kg-1) } \\
\end{array}$ \\
\hline $\mathrm{X}$ & Toksisitas & - $\quad$ Salinitas (mmhos/cm) \\
\hline $\mathrm{S}$ & Kondisi Permukaan & $\begin{array}{ll}- & \text { Kemiringan lereng }(\%) \\
- & \text { Batuan permukaan } \\
- & \text { Batuan singkapan } \\
\end{array}$ \\
\hline
\end{tabular}

iii. Selanjutnya mencocokkan (matching) masing-masing peta satuan lahan atau satuan peta tanah (SPT) dengan kriteria kesesuaian lahan untuk mendapatkan peta kesesuaian lahan.

iv. Tahap berikutnya peta kesesuaian lahan ditumpang tindih (overlay) dengan peta penggunaan lahan saat ini, sehingga akan diperoleh peta yang menunjukkan sebaran spesial kesesuaian lahan menurut karakteristik penggunaan lahan saat ini.

\section{b. Pengumpulan Data Ekonomi}

Pengumpulan data ekonomi pertanian dilakukan melalui kuisioner dan wawancara dengan petani jeruk besa yang meliputi biaya pengelolaan tanah, jumlah pohon jeruk besar, biaya tenaga kerja, pupuk yang digunakan, pestisida, produksi dan harga jual saat panen.

\section{Metode Analisis Data}

1. Analisis Kesesuaian Lahan

Analisis kesesuaian lahan untuk tanaman jeruk besar di Kecamatan Labakkang Kabupaten Pangkep yaitu dengan mencocokkan (matching) hasil identifikasi karakteristik fisik, analisis laboratorium, dan kriteria syarat tumbuh tanaman berdasarkan kriteria yang dikeluarkan departemen pertanian (Hardjowigeno dan Widiatmaka, 2007)

Hasil akhir dari keseluruhan rangkaian analisis tersebut di atas berupa peta kesesuaian lahan aktual dan 
potensial. Penetuan kelas kesesuaian lahan didasarkan pada metode matching atau perbandingan anatara data hasil analisis biofisik lahan dengan kriteria kesesuaian lahan berdasarkan FAO (1976), yang disajikan pada Tabel 2.

\section{Analisis Usaha Tani Jeruk Besar}

Analisis usahatani jeruk besar digunakan sebagai parameter kelayakan ekonomi penggunaan lahan untuk tanaman jeruk besar. Indikator yang digunakan antara lain rasio penerimaan dengan total biaya produksi dan pendapatan usaha tani. Pendapatan usahatani jeruk besar adalah total penerimaan dikurangi total pengeluaran usahatani (Soekarwati, 2005).

$$
\boldsymbol{\pi}=\mathbf{T R}-\mathbf{T C}
$$

Dimana,

$\pi=$ Pendapatan usahatani $(\mathrm{Rp} / \mathrm{Ha})$

$\mathrm{TR}=$ Total Penerimaan Usahatani

$\mathrm{TC}=$ Total Pengeluaran Usahatani

Analisis R/C rasio dilakukan untuk mengevaluasi perbandingan antara nilai produksi (penerimaan) dengan total biaya usahatani (Soekawarti, 2005). Penghasilan petani tergantung pada dua faktor utama, yaitu harga jual dan biaya usahatani.

Adapun rumus $\mathrm{R} / \mathrm{C}$ rasio adalah sebagai berikut:

$$
\mathrm{R} / \mathrm{C} \text { rasio }=\frac{\mathrm{TR}}{\mathrm{TC}}
$$

Dimana:

$\mathrm{TR}=$ total penerimaan,

$\mathrm{TC}=$ total biaya.

Total penerimaan kegiatan usaha yang diperoleh dari total produksi fisik dikalikan dengan harga produksi. Implikasi $\mathrm{R} / \mathrm{C}$ rasio yang di dapatkan ada 3 kemungkinan, yaitu

a. Jika $\mathrm{R} / \mathrm{C}$ rasio $>1$, maka kegiatan usahatani adalah menguntungkan.

b. Jika $\mathrm{R} / \mathrm{C}$ rasio $=1$, maka kegiatan usahatani adalah impas.

c. Jika $\mathrm{R} / \mathrm{C}$ rasio $<1$, maka kegiatan usahatani adalah rugi (Soekarwati, 2005).

\section{HASIL DAN PEMBAHASAN}

Hasil pengamatan lapangan dan analisis laboratorium, serta informasi iklim di wilayah Kecamatan Labakkang Kabupaten Pangkep disajikan pada Tabel 2. 
Karmiati : Optimalisasi Penggunaan Lahan untuk Tanaman Jeruk Besar (Citrus maxima Merr.) berbasis Evaluasi Lahan dan Kelayakan Ekonomi di Kecamatan Labakkang Kabupaten Pangkep

Tabel 2. Faktor Pembatas dan Upaya Perbaikan pada Kesesuaian Lahan Aktual menjadi Kesesuaian Lahan Potensial

\begin{tabular}{|c|c|c|c|c|c|c|}
\hline \multirow{2}{*}{$\begin{array}{c}\text { Unit } \\
\text { Lahan }\end{array}$} & \multirow{2}{*}{$\begin{array}{l}\text { Lahan } \\
\text { Aktual }\end{array}$} & \multirow[b]{2}{*}{ Faktor Pembatas } & \multicolumn{2}{|c|}{ Upaya Perbaikan } & \multirow[t]{2}{*}{ Jenis Perbaikan } & \multirow{2}{*}{$\begin{array}{c}\text { Lahan } \\
\text { Potensial }\end{array}$} \\
\hline & & & Sedang (+) & $\begin{array}{c}\text { Tinggi } \\
(++) \\
\end{array}$ & & \\
\hline \multirow[t]{4}{*}{$\overline{1}$} & \multirow{4}{*}{$\mathrm{N} 2 \mathrm{e}$} & - Curah hujan & + & - & Irigasi & \multirow{4}{*}{$\mathrm{N} 2 \mathrm{e}$} \\
\hline & & - N-Total & + & - & Pemupukan & \\
\hline & & - Bahaya erosi & - & - & Tidak dpt diperbaiki & \\
\hline & & - Lereng & - & - & Tidak dpt diperbaiki & \\
\hline \multirow[t]{2}{*}{2} & \multirow{2}{*}{ S2wn } & - Curah hujan & + & - & Irigasi & \multirow{2}{*}{$\mathrm{S} 1$} \\
\hline & & $-\quad \mathrm{P} 2 \mathrm{O} 5$ & + & - & Pemupukan & \\
\hline 3 & S2wn & - Curah hujan & + & - & Irigasi & $\mathrm{S} 1$ \\
\hline \multirow[t]{2}{*}{4} & \multirow{2}{*}{ S2wn } & - Curah hujan & + & 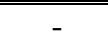 & Irigasi & \multirow{2}{*}{$\mathrm{S} 1$} \\
\hline & & - N-Total & - & ++ & Pemupukan & \\
\hline 5 & S2w & - Curah hujan & + & - & Irigasi & $\mathrm{S} 1$ \\
\hline \multirow[t]{2}{*}{$\overline{66}$} & \multirow{2}{*}{ S2wn } & - Curah hujan & + & - & Irigasi & \multirow{2}{*}{ S1 } \\
\hline & & $-\mathrm{P} 2 \mathrm{O} 5$ & + & - & Pemupukan & \\
\hline \multirow[t]{2}{*}{7} & \multirow{2}{*}{ S2wn } & - Curah hujan & + & - & Irigasi & \multirow{2}{*}{$\mathrm{S} 1$} \\
\hline & & $-\quad \mathrm{P} 2 \mathrm{O} 5$ & + & - & Pemupukan & \\
\hline
\end{tabular}

Sumber: Data Primer Setelah Diolah, 2018

Dari hasil analisis data pada Tabel 2 menunjukkan bahwa:

1. Pada unit lahan 1 dengan kemiringan lereng $24-80 \%$ dan jenis tanah regosol dengan tutupan lahan berupa pertanian lahan kering campur semak/kebun. Pada unit lahan ini, terdapat kelas kesesuaian lahan aktual untuk tanaman jeruk besar N2(e) dengan faktor pembatas, yaitu ketersediaan air (curah hujan), media perakaran (kedalaman efektif), hara tersedia (N-Total), dan tingkat bahaya erosi (bahaya erosi). Adanya faktor pembatas ini, yaitu curah hujan membutuhkan upaya perbaikan melalui irigasi secara intensif, kedalaman efektif tidak dapat dilakukan usaha perbaikan, N-Total yang rendah membutuhkan upaya perbaikan melalui pemupukan dengan dosis yang tinggi dan frekuensi yang lebih intensif, sedangkan bahaya erosi dapat diperbaiki melalui pembuatan teras atau penanaman penutup lahan dengan tingkat pengelolaan yang tinggi, usaha perbaikan bahaya erosi dapat diperbaiki apabila untuk kebutuhan pribadi namun untuk kebutuhan pengusaha tidak disarankan untuk perbaikan karena biaya sangat mahal. Dengan demikian kesesuaian lahan potensial pada unit lahan 1, yaitu N2(e). 
2. Pada unit lahan 2 dengan kemiringan lereng $0-8 \%$ dan jenis tanah laterik dengan tutupan lahan berupa pertanian lahan kering campur semak/kebun. Pada unit lahan ini, terdapat kelas kesesuaian lahan aktual untuk tanaman jeruk besar S2(wrn) dengan faktor pembatas, yaitu ketersediaan air (curah hujan), media perakaran (kedalaman efektif), dan hara tersedia (P2O5). Adanya faktor pembatas ini, yaitu curah hujan membutuhkan upaya perbaikan melalui irigasi secara intensif, kedalaman efektif tidak dapat diperbaiki, dan P2O5 membutuhkan upaya perbaikan dengan pemupukan untuk meningkatkan kandungan fosfat dalam tanah. Dengan demikian kesesuaian lahan potensial pada unit lahan 2, yaitu S2(r) karena kedalaman efektif tidak dapat diperbaiki.

3. Pada unit lahan 3 dengan kemiringan lereng 0-8\% dan jenis tanah aluvial dengan tutupan lahan berupa sawah. Pada unit lahan ini, terdapat kelas kesesuaian lahan aktual untuk tanaman jeruk besar S2(wr), dengan faktor pembatas yaitu ketersediaan air (curah hujan), dan media perakaran (kedalaman efektif). Adanya faktor pembatas ini, yaitu curah hujan membutuhkan upaya perbaikan melalui irigasi atau pengairan lahan tanaman jeruk besar, sedangkan kedalaman efektif tidak dapat dilakukan perbaikan.

4. Pada unit lahan 4 dengan kemiringan lereng $0-8 \%$ dan jenis tanah aluvial dengan tutupan lahan berupa lahan kering campur semak atau kebun. Pada unit lahan ini, terdapat kelas kesesuaian lahan aktual untuk tanaman jeruk besar S2(wrn) dengan faktor pembatas, yaitu ketersediaan air (curah hujan), media perakaran (kedalaman efektif), dan hara tersedia (N-Total). Adanya faktor pembatas ini, yaitu curah hujan membutuhkan upaya perbaikan melalui irigasi secara intensif, kedalaman efektif tidak dapat diperbaiki, dan N-Total membutuhkan upaya perbaikan dengan pemupukan untuk meningkatkan kadar $\mathrm{N}$ dalam tanah.

5. Pada unit lahan 5 dengan kemiringan lereng 0-8\% dan jenis tanah aluvial dengan tutupan lahan berupa tambak. Pada unit lahan ini, terdapat kelas kesesuaian aktual untuk tanaman 
jeruk besar S2(wr), dengan faktor pembatas yaitu ketersediaan air (curah hujan), dan media perakaran (kedalaman efektif). Adanya faktor pembatas ini, yaitu curah hujan membutuhkan upaya perbaikan melalui irigasi atau pengairan lahan tanaman jeruk besar, sedangkan kedalaman efektif tidak dapat dilakukan perbaikan.

6. Pada unit lahan 6 dengan kemiringan lereng $0-8 \%$ dan jenis tanah laterik dengan tutupan lahan berupa lahan sawah. Pada unit lahan ini, terdapat kelas kesesuaian lahan aktual untuk tanaman jeruk besar S2(wrn), dengan faktor pembatas, yaitu ketersediaan air (curah hujan), media perakaran (kedalaman efektif), dan hara tersedia (P2O5). Adanya faktor pembatas ini, yaitu curah hujan membutuhkan upaya perbaikan melalui irigasi secara intensif, kedalaman efektif tidak dapat diperbaiki, dan P2O5 membutuhkan upaya perbaikan dengan pemupukan untuk meningkatkan kandungan fosfat dalam tanah. Dengan demikian kesesuaian lahan potensial pada unit lahan 2, yaitu S2(r) karena kedalaman efektif tidak dapat diperbaiki.

7. Pada unit lahan 7 dengan kemiringan lereng $0-8 \%$ dan jenis tanah regosol dengan pertanian lahan kering campur semak/kebun. Pada unit lahan ini, terdapat kelas kesesuaian lahan aktual untuk tanaman jeruk besar S2(wrn), dengan faktor pembatas, yaitu ketersediaan air (curah hujan), media perakaran (kedalaman efektif), dan hara tersedia (P2O5). Adanya faktor pembatas ini, yaitu curah hujan membutuhkan upaya perbaikan melalui irigasi secara intensif, kedalaman efektif tidak dapat diperbaiki, dan P2O5 membutuhkan upaya perbaikan dengan pemupukan untuk meningkatkan kandungan fosfat dalam tanah. Dengan demikian kesesuaian lahan potensial pada unit lahan 2, yaitu S2(r) karena kedalaman efektif tidak dapat diperbaiki. Pada unit lahan 7 faktor pembatasnya sama dengan unit lahan 6 .

Potensi kesesuaian lahan aktual yang ada pada setiap unit-unit lahan dan kesesuaian lahan potensial serta adanya usaha-usaha perbaikan pada kelas kesesuaian lahan S2 dan N2 yang 
mengalami penurunan kelas kesesuaian lahan akan memberikan masukan dan tingkat pengelolaan sesuai kebutuhan lahan tersebut sehingga hasil akhir yang diharapkan adalah peningkatan kulitas biofisik lahan dan meningkatnya produktifitas lahan dari sebelumnya yang tidak sesuai akan dapat ditingkatkan lebih tinggi dengan upaya perbaikan dari faktor pembatas yang ada pada lahan tersebut, sehingga kesesuaian lahan potensial menjadi N2. Data potensi kelas kesesuaian lahan aktual dan potensial tanaman jeruk besar di Kecamatan Labakkang Kabupaten Pangkep disajikan pada Tabel 3.

Tabel 3. Potensi kelas kesesuaian lahan aktual dan potensial tanaman jeruk besar di Kecamatan Labakkang Kabupaten Pangkep

\begin{tabular}{ccc}
\hline \hline \multirow{2}{*}{ Unit Lahan } & \multicolumn{2}{c}{ Kesesuaian Lahan } \\
\cline { 2 - 3 } & Aktual & Potensial \\
\hline \hline 1 & N2e & N2e \\
\hline \hline $2,3,4,6,7$ & S2wrn & S2r \\
\hline \hline 5 & S2wr & S2r \\
\hline \hline
\end{tabular}

Analisis Usaha Tani Tanaman Jeruk Besar

Usaha tani yang dikelolah oleh petani di wilayah penelitian umumnya adalah usaha yang dilakukan oleh petani dan keluarganya pada lahan perkebunan milik mereka sendiri maupun lahan keluarga lainnya. Pengelolaan jeruk besar di lokasi penelitian umumnya masih kurang optimum, terlihat dari input yang diberikan berupa pengelolaan lahan pertanian, pemupukan, serta penataan lahan. Hal ini berdampak pada tingkat produktifitas lahan dan produktifitas jeruk cenderung masih dibawah standar.
Produksi dalam usaha tani jeruk besar ialah jumlah yang dihasilkan oleh luas lahan responden dalam sekali panen. Hasil produksi tersebut berupa buah jeruk besar yang dihasilkan dari usaha tani jeruk besar. Adapun pendapatan merupakan selisih antara total penerimaan dikurangi total biaya usaha tani jeruk besar. Sedangkan penerimaan merupakan produksi yang dikurangi dengan total biaya usaha tani jeruk besar.

Berdasarkan hasil hasil wawancara dengan responden petani jeruk besar di Kecamatan Labakkang Kabupaten Pangkep diketahui bahwa lahan jeruk besar pada umumnya merupakan lahan 
Karmiati : Optimalisasi Penggunaan Lahan untuk Tanaman Jeruk Besar (Citrus maxima Merr.) berbasis Evaluasi Lahan dan Kelayakan Ekonomi di Kecamatan Labakkang Kabupaten Pangkep

dengan status milik sendiri dengan luas panen pertama dan kedua harganya 0,40-1,70 ha dengan rata-rata 0,88 ha. Rp.2500/buah, namun panen ketiga Pengelolaan usaha tani jeruk besar pada biasanya harga sudah turun berkisar umumnya dikelolah dengan tenaga kerja Rp.2000/buah. Sistem perhitungan buah yang berasal dari keluarga sendiri seperti jeruk besar pada panen ketiga sudah tidak pemupukan, pemangkasan dan dihitung perbuah lagi tapi biasa dua buah penyiangan rumput liar. Sedangkan untuk dihitung dengan satu buah saja. upah panen dan pengangkutan dikerjakan Berdasarkan Tabel 4, menunjukkan oleh pengepul jeruk besar yang datang bahwa produksi ata-rata/responden langsung mengambil hasil panen di lahan sebanyak 2.458 buah, rata-rata petani.

Panen pada umumnya di lakukan penerimaan/responden sebesar Rp. 3.807.500, rata-rata biaya/responden satu kali dalam satu tahun, namun sebesar Rp.2.211.333, dan rata-rata pengepul biasanya mengambil hasil panen pendapatan/responden sebesar Rp. tiga kali pengambilan sampai seluruh 5.911.667/tahun. jeruk besar telah habis di pohonnya. Pada

Tabel 4. Produksi dan Pendapatan Responden Jeruk Besar di Kecamatan Labakkang Kabupaten Pangkep

\begin{tabular}{ccc}
\hline No. & Uraian & Rata-Rata/Responden (thn) \\
\hline \hline 1 & Produksi (Biji) & 2.458 \\
\hline \hline 2 & Harga (Rp.) & 2.300 \\
\hline 3 & Penerimaan (Rp.) & 3.807 .500 \\
\hline 4 & Biaya (Rp.) & 2.211 .333 \\
\hline 5 & Pendapatan (Rp.) & 5.911 .667 \\
\hline Sumber: Data Primer Setelah Diolah, 2018
\end{tabular}

Kelayakan usaha tani jeruk besar merupakan analisis untuk mengetahui apakah usaha tani tersebut layak atau tidak diusahakan. Untuk mengetahui tingkat kelayakan usaha tani jeruk besar di daerah penelitian maka analisis dengan menggunakan R/C Ratio. Analisis R/C Ratio dilakukan untuk mengevaluasi perbandingan antara nilai produksi (penerimaan) (TR) dengan total biaya usaha tani (TC).

$\mathrm{R} / \mathrm{C}=\frac{\mathrm{TR}}{\mathrm{TC}}$ 
$\mathrm{R} / \mathrm{C}=\frac{3.807 .500}{2.211 .333}=1,72$

Analisis R/C ratio dengan membandingkan antara nilai produksi (penerimaan) jeruk besar dan total biaya usaha tani jeruk besar diperoleh $\mathrm{R} / \mathrm{C}$ sebesar 1,72. Hal ini menginformasikan bahwa usaha tani jeruk besar yang dikelolah oleh petani di Kecamatan Labakkang Kabupaten Pangkep "Layak" atau dengan bahasa lain menguntungkan bagi petani jeruk besar.

\section{Otimalisasi Penggunaan Lahan}

Optimalisasi penggunaan lahan untuk tanaman jeruk besar yang paling optimal di peroleh dari evaluasi yang

Kelas kesesuaian lahan aktual pada unit lahan 1 yaitu N2e, unit lahan 2,3,4,6,7 S2wrn dan unit lahan 5 S2wr sedangkan kelas kesesuaian lahan potensial pada unit lahan $1 \mathrm{~N} 2 \mathrm{e}$, unit lahan 2,3,4,6,7 S2r dan unit lahan $5 \mathrm{~S} 2 \mathrm{r}$.

2. Faktor pembatas kelas kesesuaian lahan aktual pada unit lahan 1 yaitu N2e dengan faktor pembatas ketersediaan air, media perakaran, hara tersedia, serta tingkat bahaya erosi. Kelas kesesuaian lahan aktual 2,3,4,6 yaitu S2wrn dengan faktor tertinggi dengan tinkgkat pendapat ekonomi yang di dapatkan dari salah satu responden yang berada pada di Desa Kassilowe dengan pendapatan Rp. 13.000.000 (Lihat Lampiran 8) dan kesesuaian lahan potensial S2r.

\section{KESIMPULAN}

Berdasarkan hasil penelitian evaluasi kesesuaian lahan dan analisis usaha tani jeruk besar di Kecamatan Labakkang Kabupaten Pangkep, maka dapat disimpulkan bahwa:

1. Evaluasi kesesuaian lahan aktual dan potensial di lokasi penelitian menunjukkan:

pembatas ketersediaan air, media perakaran, serta hara tersedia. Kelas kesesuaian lahan aktual pada unit lahan 5 yaitu S2wr dengan faktor pembatas ketersediaan air dan media perakaran.

3. Upaya perbaikan kelas kesesuaian lahan N2 (sesuai marginal) dapat diperbaiki melalui pembuatan teras atau penanaman penutupan lahan, namun ini membutuhkan biaya yang sangat mahal. Sedangkan kelas kesesuaian S2 (cukup sesuai) dengan 
Karmiati : Optimalisasi Penggunaan Lahan untuk Tanaman Jeruk Besar (Citrus maxima Merr.) berbasis Evaluasi Lahan dan Kelayakan Ekonomi di Kecamatan Labakkang Kabupaten Pangkep

faktor pembatas kedalaman efektif tidak dapat diperbaiki (given).

4. Analisis kelayakan ekonomi usaha tani jeruk besar di Kecamatan Labakkang Kabupaten Pangkep dengan $\mathrm{R} / \mathrm{C}$ ratio 1,72 layak atau dengan bahasa lain menguntungkan bagi petani jeruk besar.

5. Optimalisasi yang diperoleh dari evaluasi lahan yang tertinggi dengan tingkat pendapatan ekonomi di dapatkan di Desa Kassilowe dengan pendapatan tertinggi seorang petani sebesar Rp.13.000.000 dan terdapat pada kelas kesesuaian lahan potensial S2r.

\section{DAFTAR PUSTAKA}

Abdullah, T.S. 1993. Survey Tanah dan Evaluasi Lahan. Penebar swadaya, Jakarta.

Adiwilaga, Ishak. 2008. Ilmu Usaha Tani. Pertania Universitas Pajajaran. Bandung.

Arsyad Sitanala. 2006. Konservasi Tanah dan Air. Bogor. IPB Press.

Arsyad Sitanala. 1999. Petunjuk Teknis Evaluasi Lahan. Pusat Penelitian Tanah dan Agroklimat. Bogor.

Arsyad Sitanala. 1989. Konservasi Tanah dan Air. Bandung. Institut Pertanian Bogor.

Buckman dan Brady. 2000. Unsure hara dalam tanah. Jurusan Ilmu Tanah.

Davidso., D.A. 1992. The Evaluation of Land Resourrces. Longman Scientific \& Technical, New York.
Djaenuddin, Marwah H, dkk. 2003. Kriteria Kesesuaian Lahan untuk Komoditas Pertanian. Jakarta: Pusat Penelitian Tanah dan Agroklimatologi, Balai Penelitian dan Pengembangan Pertanian, Bogor.

FAO. 1976. A Framework for Land Evaluation. Soil Resources Management and Conservation Service Land and Water Development Division. FAO Soil Bulletin No. 32. FAO-UNO, Rome.

FAO, 1983. World Food Security: a Reappraisal of the Concepts and Approaches. Director Generals Report, Rome.

Foth, Henry D. 1998. Dasar-dasar Ilmu Tanah. Terjemahan: Pubayanti, E.D. Lukyowati dan R. Triwulatsih. Gajah Mada Universitas Press, Yogyakarta.

Hardjowigeno, Widiatmika. 2007. Kesesuaian Lahan dan Perencanaan Tataguna Tanah. Bogor: Institut Pertanian Bogor.

Hernanto Fadholi. 1988. Ilmu Usahatani. Seri Pertanian.

Indranada, Hendry K. 1986. Pengelolaan Kesuburan Tanah. Jakarta: PT Bina Aksara.

Mather, A.S. 1986. Land Use. Logman. London New York.

M. Ramli dan Sunanto. 2009. Sumber Daya Fisik Wilayah dan Tata Guna Lahan. Jurusan Ilmu Tanah, Fakultas Pertanian IPB. Bogor.

Muhaymin. 2009. Analisis Kelayakan Finansial Jeruk Besar. Purbalinggo Jawa Timur.

Landon, JR. 1984. Booker tropical soil manual. Booker Agriculture International Limited, England.

Rahim, S.E. 2000. Pengendalian Erosi Tanah dalam Rangka Pelestarian Lingkungan Hidup. Jakarta: Bumi Aksara. 
Karmiati : Optimalisasi Penggunaan Lahan untuk Tanaman Jeruk Besar (Citrus maxima Merr.) berbasis Evaluasi Lahan dan Kelayakan Ekonomi di Kecamatan Labakkang Kabupaten Pangkep

Rayes, M. Luthfi. 2006. Metode Sinukaban, N. 1986. Dasar-dasar Inventarisasi Sumber Daya Lahan. Konservasi Tanah dan Perencanaan Yogyakarta: Penerbi: Andi.

Ritung S, Wahyunto, dkk. 2007. Panduan Evaluasi Kesesuaian Lahan dengan Contoh Peta Arahan Penggunaan Lahan. Balai Penelitian Tanah dan World Agoforestry Center (ICRAF). Bogor.

Sitorus, Santun. 1985. Evaluasi Sumber Pertanian Konservasi. Jurusan Tanah, Institut Pertanian Bogor. Bogor.

Sutedjo, M. M dan A. G. Kartasapoetra, 1991. Pengantar Ilmu Tanah. Rineka Cipta. Jakarta.

Poerwowidodo. 1993. Telaah Kesuburan Tanah. Penerbit Angkasa Bandung. Daya Lahan. Bandung: Penerbit Tarsito. 